\author{
Jarosław STRZAŁKOWSKI ${ }^{1}$ \\ Halina GARBALIŃSKA ${ }^{2}$
}

\title{
TRANSMITANCJE CIEPLNE DWUWARSTWOWYCH ŚCIAN ZEWNETRZNYCH ZRÓŻNICOWANYCH MATERIAŁEM NOŚNYM
}

\begin{abstract}
W niniejszej pracy poddano analizie zbiór danych dotyczących dynamicznych charakterystyk cieplnych ścian zewnętrznych o różnie dobranej pod względem materiałowym warstwie konstrukcyjnej. Główny cel stanowiło poszukiwanie rozwiązań przegród, które nie tylko zapewniać będą odpowiednio wysoką izolacyjność cieplną, ale które umożliwią magazynowanie energii oraz odpowiednie jej wykorzystanie w zależności od zmieniających się warunków środowiska zewnętrznego. Obliczenia wykonano dla przegród z warstwą nośną z rozmaitych kompozytów betonowych (na bazie kruszyw lekkich keramzytu i popiołoporytu, w dwóch wariantach z domieszką napowietrzającą i bez), betonu komórkowego, litego drewna klejonego oraz innych typowych materiałów małowymiarowych: cegły silikatowej oraz cegły dziurawki. Wyznaczono rozkłady transmitancji cieplnej w zależności od przyjętego okresu wahań temperatury. Obliczono również współczynniki tłumienia oraz powierzchniowe pojemności cieplne przegród dla okresów wahań temperatury równych $24 \mathrm{~h}$ oraz $168 \mathrm{~h}$. Wyniki wskazują, że uwzględnienie ciepła właściwego materiałów umożliwia bardziej precyzyjną ocenę przegrody pod względem cieplnym. Bardzo dobre właściwości tłumiące przegrody uzyskano dla kompozytów betonowych oraz litego drewna klejonego. Otrzymane dane sugerują, że tego typu rozwiązania powodują zredukowanie amplitud chwilowych strumieni ciepła w krótkich okresach wahań temperatury w porównaniu do materiałów o niskim cieple właściwym. Zaostrzone przepisy Dyrektywy 2010/31/UE wskazują na potrzebę szerszego rozpatrzenia problemu i zasadność analizowania przegród w niestacjonarnych warunkach temperaturowych.
\end{abstract}

Słowa kluczowe: ściany zewnętrzne, transmitancja cieplna, pojemność cieplna, dynamiczne charakterystyki cieplne, ciepło właściwe

\footnotetext{
1 Autor do korespondencji: Jarosław Strzałkowski, Zachodniopomorski Uniwersytet Technologiczny w Szczecinie, al. Piastów 50, 70-311 Szczecin, 91-449-43-41, jstrzalkowski@zut.edu.pl

${ }^{2}$ Halina Garbalińska, Zachodniopomorski Uniwersytet Technologiczny w Szczecinie, al. Piastów 50, 70-311 Szczecin, 91-449-42-91, Halina.Garbalinska@zut.edu.pl
} 


\section{Wstęp}

Wprowadzenie nowej dyrektywy unijnej 2010/31/UE dotyczącej charakterystyki energetycznej budynków nakłada na projektantów konieczność spełnienia coraz bardziej restrykcyjnych wymagań dotyczących energooszczędności. Wdrażane zmiany mają zaskutkować powstawaniem po $2021 \mathrm{r}$. wyłącznie budynków o niemal zerowym zużyciu energii. Dlatego też istotnym aspektem może być poszukiwanie rozwiązań przegród, które nie tylko zapewniać będą odpowiednio wysoką izolacyjność cieplną, ale które umożliwią magazynowanie energii oraz odpowiednie jej wykorzystanie w zależności od zmieniających się warunków środowiska zewnętrznego. W niniejszej pracy przeanalizowano wpływ użytego materiału warstwy nośnej, w dwuwarstwowej ścianie zewnętrznej, na transmitancję cieplną dla różnych okresów wahań temperatury.

\section{Dynamiczne charakterystyki cieplne}

\subsection{Opis przegrody}

W artykule poddano analizie ściany zewnętrzne dwuwarstwowe $\mathrm{z}$ wariantowo przyjętym materiałem konstrukcyjnym. Schemat analizowanej przegrody przedstawiono na rysunku 1 .

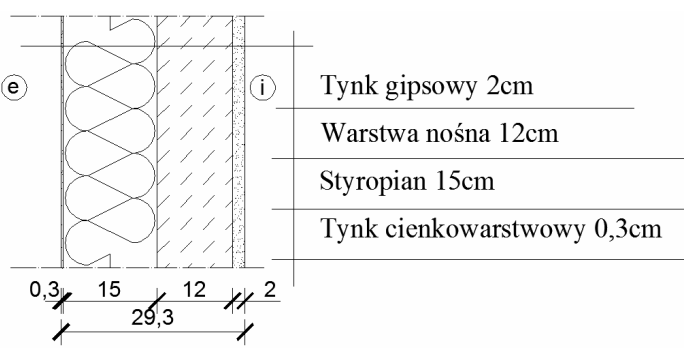

Rys. 1. Schemat przegrody poddanej analizie

Fig. 1. Scheme of the analysed wall

Przyjęto grubość warstwy nośnej $12 \mathrm{~cm}$ - identyczną dla wszystkich wariantów, tak aby istniała możliwość bezpośredniego porównania otrzymanych wyników. Ustalona grubość została przyjęta tak, aby nie faworyzować żadnego $\mathrm{z}$ wariantów. Punktem wyjścia był fakt, że ściany z drewna monolitycznego projektuje się do grubości $12 \mathrm{~cm}$. Założono ponadto, że wszystkie przegrody powinny spełniać minimalne wymagania dotyczące izolacyjności cieplnej, zgodnie z [4]. Osiągnięto to poprzez zastosowanie stałej grubości materiału termoizolacyjnego równego $15 \mathrm{~cm}$. W obliczeniach uwzględniono również warstwy tynków oraz powierzchniowe opory przejmowania ciepła. Parametry modelowanej przegrody podano w tabeli 1 . 
Tabela 1. Parametry poszczególnych warstw ściany zewnętrznej

Table 1. Parameters of the particular layers of the external wall

\begin{tabular}{|c|c|c|c|c|c|}
\hline Lp. & Nazwa & $\begin{array}{c}\boldsymbol{d} \\
\mathrm{m}\end{array}$ & $\begin{array}{c}\lambda \\
\mathrm{W} /(\mathrm{m} \cdot \mathrm{K})\end{array}$ & $\begin{array}{c}\boldsymbol{\rho} \\
\mathrm{kg} / \mathrm{m}^{3}\end{array}$ & $\begin{array}{c}\boldsymbol{c}_{\boldsymbol{v}} \\
\mathrm{MJ} /\left(\mathrm{m}^{3} \cdot \mathrm{K}\right)\end{array}$ \\
\hline 1 & tynk gipsowy & 0,020 & 0,40 & 1000 & 1,00 \\
\hline 2 & warstwa nośna & 0,120 & tab. 2 & tab. 2 & tab. 2 \\
\hline 3 & styropian & 0,150 & 0,04 & 30 & 0,042 \\
\hline 4 & $\begin{array}{c}\text { tynk cienkowar- } \\
\text { stwowy }\end{array}$ & 0,003 & 1,00 & 1800 & 1,80 \\
\hline
\end{tabular}

Analizie poddano dziewięć przegród o różnie dobranych materiałach konstrukcyjnych, których podstawowe właściwości fizyczne przedstawiono w tabeli 2. Pierwsze cztery materiały to kompozyty betonowe bazujące na kruszywach lekkich: keramzycie $(\mathrm{K})$ i kruszywie popiołoporytowym $(\mathrm{P})$, w dwóch wariantach - napowietrzonym (A) oraz nienapowietrzonym $(\mathrm{N})$. Receptury betonów oraz ich szczegółowa charakterystyka znajduje się w [5][5]. Obliczenia wykonano również dla ściany żelbetowej oraz typowych rozwiązań bazujących na elementach małowymiarowych dostępnych na rynku. Dodatkowo sprawdzono również system HBE, który jako element nośny wykorzystuje lite drewno sosnowe lub świerkowe, klejone warstwowo. Właściwości fizyczne tych materiałów przyjęto na podstawie normy [3].

Tabela 2. Materiałowe parametry poszczególnych warstw nośnych

Table 2. Material parameters of the particular load bearing layers

\begin{tabular}{|c|c|c|c|c|}
\hline Lp. & Materiat & $\begin{array}{c}\lambda \\
\mathrm{W} /(\mathrm{m} \cdot \mathrm{K})\end{array}$ & $\begin{array}{c}\boldsymbol{\rho} \\
\mathrm{kg} / \mathrm{m}^{3}\end{array}$ & $\begin{array}{c}\boldsymbol{c}_{\boldsymbol{v}} \\
\mathrm{MJ} /\left(\mathrm{m}^{3} \cdot \mathrm{K}\right)\end{array}$ \\
\hline 1 & $\mathrm{~K} / \mathrm{N}$ & 0,68 & 1,42 & 1,740 \\
\hline 2 & $\mathrm{~K} / \mathrm{A}$ & 0,46 & 1,12 & 1,540 \\
\hline 3 & $\mathrm{P} / \mathrm{N}$ & 1,05 & 1,82 & 1,770 \\
\hline 4 & P/A & 0,69 & 1,54 & 1,610 \\
\hline 5 & Żelbet & 1,70 & 2,20 & 1,848 \\
\hline 6 & Beton komórkowy 600 & 0,21 & 0,60 & 0,504 \\
\hline 7 & Silikat drążony & 0,80 & 1,60 & 1,408 \\
\hline 8 & Cegła kratówka & 0,56 & 1,30 & 1,144 \\
\hline 9 & System HBE & 0,16 & 0,55 & 1,381 \\
\hline
\end{tabular}

\subsection{Metoda badawcza}

Obliczenia dynamicznych charakterystyk cieplnych wykonano na podstawie [2]. Dla wszystkich dziewięciu wariantów i różnych okresów wahań temperatury wyznaczono macierze przejścia $\mathrm{Z}$. Na tej podstawie możliwe jest powiązanie amplitud zespolonych temperatury i strumienia ciepła pod jednej stronie $\mathrm{z}$ warunkami po stronie przeciwnej przegrody, co przedstawia zależność: 


$$
\left[\begin{array}{l}
\widehat{\Theta}_{e} \\
\hat{\mathrm{q}}_{e}
\end{array}\right]=\left[\begin{array}{ll}
Z_{11} & Z_{12} \\
Z_{21} & Z_{22}
\end{array}\right] \cdot\left[\begin{array}{l}
\widehat{\Theta}_{i} \\
\hat{\mathrm{q}}_{i}
\end{array}\right]
$$

Powyższe równanie umożliwia określenie wielkości amplitudy zespolonej temperatury i strumienia ciepła, jeżeli znane są te wartości po drugiej stronie. Amplitudy zespolone pozwalają z kolei na określenie wielkości amplitudy harmonicznie zmieniającej się funkcji (moduł tej liczby) oraz przesunięcia fazowego (argument z liczby zespolonej). Amplitudy zespolone przedstawia się jako postać wykładniczą liczby zespolonej w następującej formie:

$$
\begin{aligned}
& \widehat{\Theta}_{ \pm}=|\widehat{\Theta}| \cdot e^{ \pm i \psi} \\
& \widehat{\mathrm{q}}_{ \pm}=|\widehat{\mathrm{q}}| \cdot e^{ \pm i \varphi}
\end{aligned}
$$

Zakłada się, że temperatury po obu stronach przegrody oscylują wokół wartości średnich, a strumienie ciepła zmieniają się wokół wartości równej:

$$
\bar{q}=U \cdot\left(\Theta_{i}-\Theta_{e}\right)
$$

Na podstawie równania (1) obliczono także wartości transmitancji cieplnej $Y_{12}$ dla zmiennego okresu wahań temperatury przy powierzchniach od 1 do 720 godzin. Obliczono także współczynniki tłumienia $f$ oraz wewnętrzne powierzchniowe pojemności cieplne $K_{l}$ dla dwóch okresów wahań równych 24 oraz 168 godzin. Szczegółowy sposób obliczeń przedstawiono w [1].

\section{Wyniki analizy}

Na rysunku 2 przedstawiono współczynniki tłumienia $f$ dla okresu wahań równego $24 \mathrm{~h}$. Widoczna jest wyraźna dysproporcja między ścianą wykonaną $\mathrm{z}$ betonu komórkowego a pozostałymi materiałami. Najlepsze parametry tłumienia uzyskano dla systemu HBE, który w czasie nagłych zmian temperatury zewnętrznej, w krótkich okresach wahań uzyskuje transmitancję cieplną na poziomie 15-20\% wartości współczynnika przenikania ciepła $U$. Także ściany $\mathrm{z}$ warstwami nośnymi wykonanymi z betonu zbrojonego i lekkich kompozytów betonowych zapewniały dosyć dobre współczynniki tłumienia. Kompozyty betonowe pomimo mniejszej gęstości objętościowej wykazywały bardzo dobre parametry w porównaniu do żelbetu.

Rysunek 3 przedstawia współczynniki tłumienia dla okresu wahań temperatury równego jeden tydzień. Dla tak przyjętego okresu beton komórkowy uzyskał wartości zbliżone do jedności. Ponownie wyróżnia się system HBE, którego transmitancja cieplna jest o ok. $18 \%$ mniejsza niż obliczeniowy współczynnik przenikania ciepła $U$. Przy dużych wahaniach temperatury zewnętrznej daje to możliwość zredukowania wielkości wahań temperatury w pomieszczeniu. 


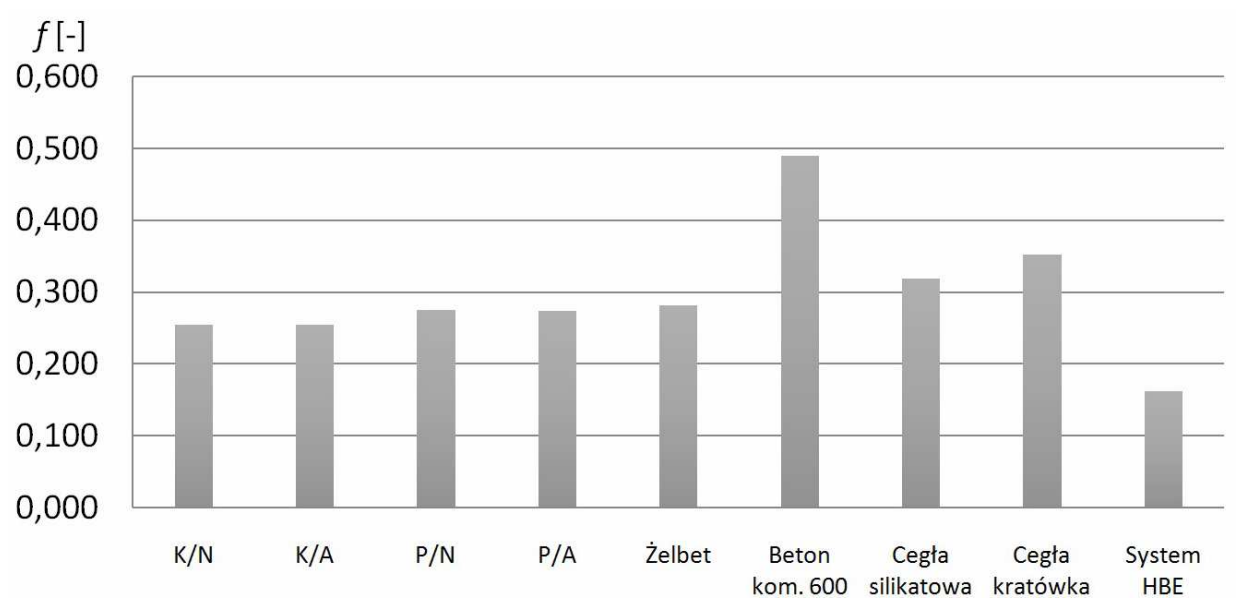

Rys. 2. Współczynniki tłumienia dla okresu wahań równego 24 h

Fig. 2. Damping coefficients for the temperature fluctuations period of $24 \mathrm{~h}$

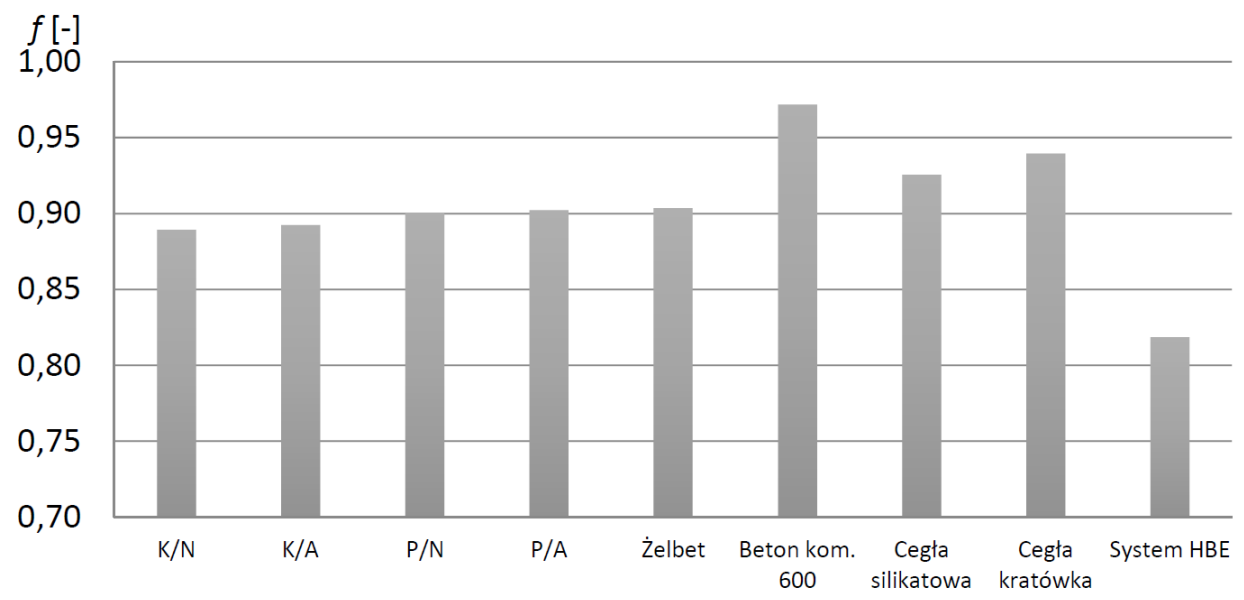

Rys. 3. Współczynniki tłumienia dla okresu wahań równego $168 \mathrm{~h}$

Fig. 3. Damping coefficients for the temperature fluctuations period of $168 \mathrm{~h}$

Na rysunku 4 zestawiono rozkłady transmitancji cieplnych w zależności od przyjętego okresu wahań temperatury powierzchni przegrody. Przedstawiono wyłącznie cztery wybrane krzywe, które najlepiej oddają różnice między materiałami o różnych właściwościach cieplnych. Otrzymane wykresy charakteryzują się asymptotą poziomą równą współczynnikowi przenikania ciepła $U$ danego wariantu. Istotny jest sposób w jaki krzywa transmitancji przyrasta w krótkich okresach wahań temperatury. Im łagodniejszy jest przyrost transmitancji, tym chwilowa gęstość strumienia ciepła będzie mniejsza niż wartość średniej gęstości strumienia w funkcji współczynnika przenikania ciepła. Najkorzystniejsze krzywe transmitancji uzyskano dla systemu HBE. Nawet dla okresu wahan równego 150 godzin 


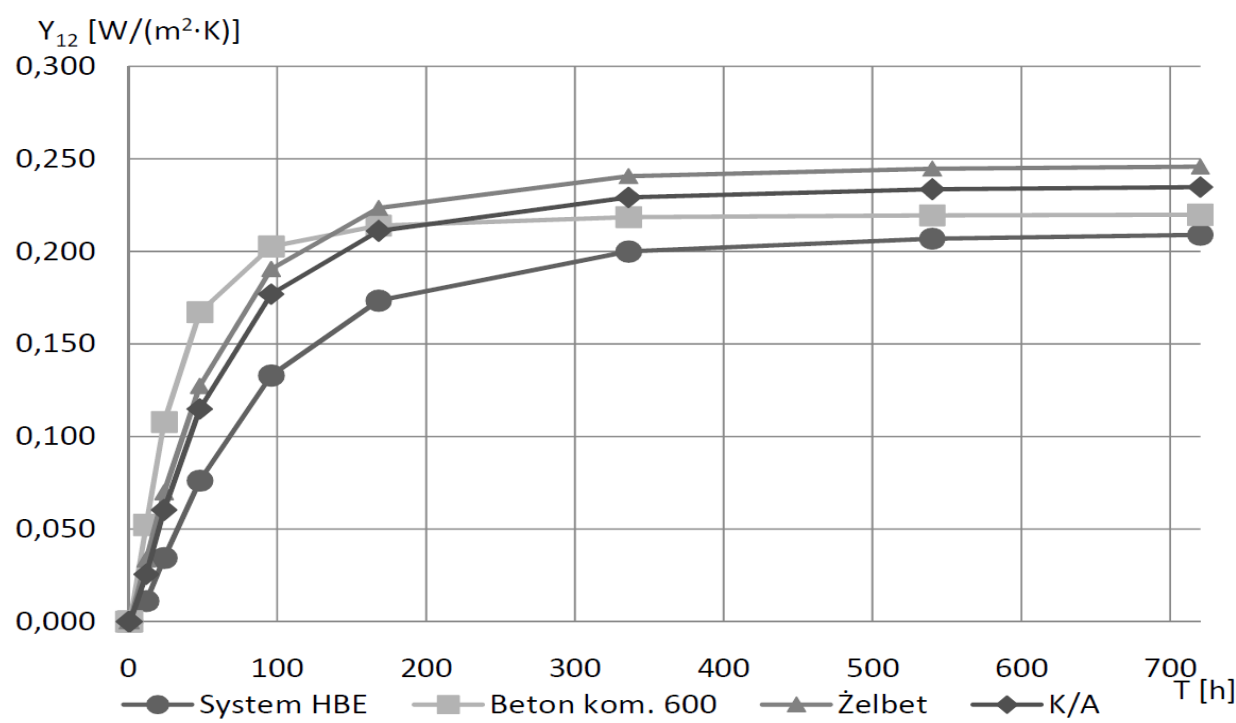

Rys. 4. Transmitancja cieplna ścian zewnętrznych w zależności od okresu wahań

Fig. 4. Thermal transmittance of external walls in correlation with the fluctuation period

taka konstrukcja zapewnia zdecydowanie mniejsze wartości chwilowego strumienia ciepła, niż wartości uzyskane na podstawie współczynnika przenikania ciepła. Natomiast konstrukcja z warstwą nośną z betonu komórkowego bardzo szybko uzyskuje poziom wartości równej współczynnikowi $U$, co świadczy o zdecydowanie słabszych parametrach tłumienia takiej przegrody. Dosyć dobrze plasują się również konstrukcje wykonane na bazie betonu, mimo że współczynniki przenikania ciepła $U$ tych rozwiązań są większe.

W niniejszym artykule porównano również powierzchniowe pojemności cieplne. Wartości dla okresu wahań równego $24 \mathrm{~h}$ przedstawiono na rysunku 5. Największe pojemności otrzymano dla wariantów z warstwą nośną z kompozytów betonowych i żelbetu. Jest to efekt odpowiedniego dobrania ciepła

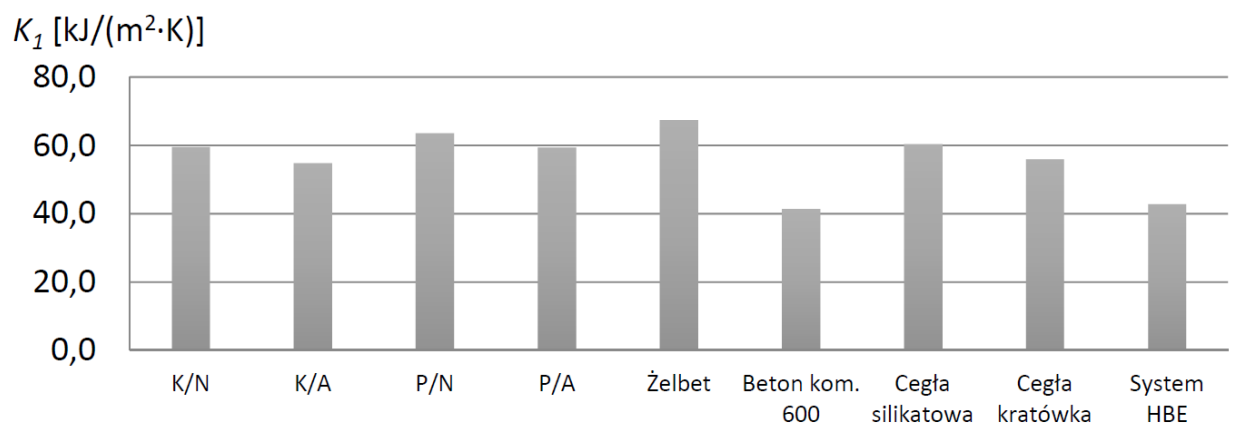

Rys. 5. Wewnętrzne powierzchniowe pojemności cieplne dla okresu wahań równego $24 \mathrm{~h}$

Fig. 5. Internal surface heat capacities for the $24 \mathrm{~h}$ fluctuation period 
właściwego $c_{v}$ i współczynnika przenikania ciepła $\lambda$. Zdecydowanie mniejsze wartości otrzymano dla betonu komórkowego i systemu HBE. Wynika to ze stosunkowo niskiej przewodności cieplnej tych materiałów.

Dla dłuższych okresów wahań temperatury (168 godzin - rys. 6) uzyskano jeszcze większe różnice w zależności od zastosowanego materiału warstwy nośnej. Im dłuższy okres wahań, tym większy wpływ na pojemność cieplną będzie miało ciepło właściwe materiału, natomiast współczynnik przewodzenia ciepła $\lambda$ nie jest już tak istotny. Dlatego też bardzo niekorzystnie w zestawieniu plasuje się beton komórkowy, którego powierzchniowa pojemność cielna jest prawie trzykrotnie mniejsza niż pojemność przegród betonowych.

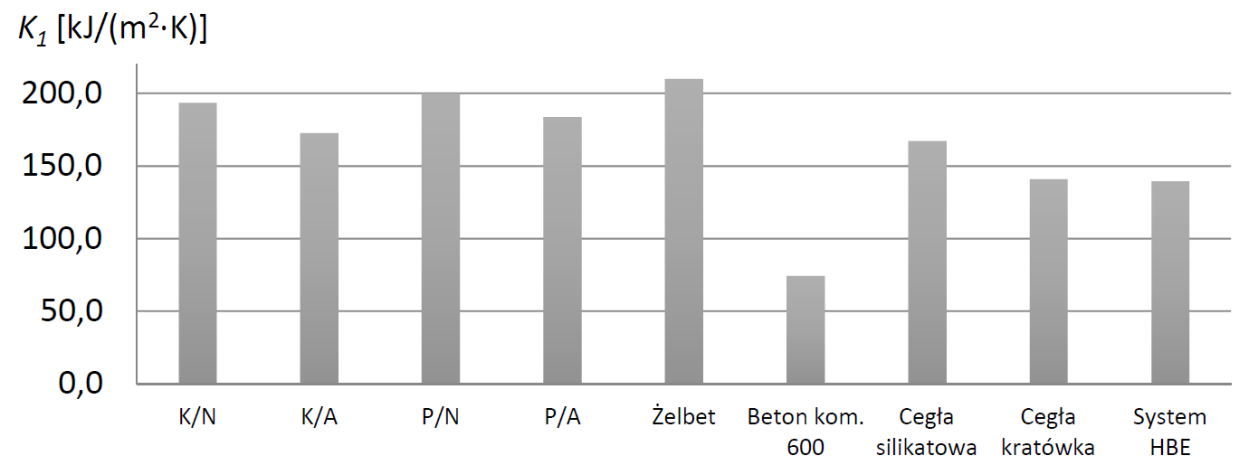

Rys. 6. Wewnętrzne powierzchniowe pojemności cieplne dla okresu wahań równego 168h

Fig. 6. Internal surface heat capacities for the $168 \mathrm{~h}$ fluctuation period

\section{Podsumowanie}

Analiza przegród budowlanych z aspekcie dynamicznych właściwości cieplnych użytych materiałów w konstrukcji ściany, umożliwia szersze oraz bardziej precyzyjne określenie zachowania się przegrody budowlanej. Uwzględnienie w obliczeniach wartości ciepła właściwego materiałów skutkuje dużym zróżnicowaniem wyników uzyskanych dla różnych materiałów warstwy nośnej przegrody. Sam współczynnik przenikania ciepła nie daje możliwości porównania rozmaitych systemów budowlanych w złożonych warunkach cieplnych.

Zastosowanie materiałów o dużym cieple właściwym zapewnia istotną redukcję amplitudy chwilowej gęstości strumienia ciepła dla okresu wahań temperatury równego nawet jeden tydzień. Uzasadnione zatem jest wykorzystanie materiałów takich jak kompozyty betonowe, czy drewno klejone jako materiały, które mogą zredukować amplitudę strumienia ciepła oraz temperatury w sytuacji występowania dużych amplitud temperatury środowiska zewnętrznego.

Transmitancja cieplna i inne parametry dynamiczne dają zatem możliwość lepszych i bardziej precyzyjnych analiz służących projektowaniu przegród charakteryzujących się większą energooszczędnością. 


\section{Literatura}

[1] Garbalińska H., Strzałkowski J.: Analiza porównawcza dynamicznych charakterystyk cieplnych przegród wykonanych z różnych kompozytów betonowych, Inżynieria i Budownictwo, nr 6, 2012, s. 307-311.

[2] PN-EN ISO 13786:2008: Cieplne właściwości użytkowe komponentów budowlanych, Dynamiczne charakterystyki cieplne, Metody obliczania.

[3] PN-EN ISO 6946:1999: Komponenty budowlane i elementy budynku, Opór cieplny i współczynnik przenikania ciepła, Metoda obliczania.

[4] Rozporządzenie Ministra Transportu, Budownictwa i Gospodarki Morskiej z dnia 5 lipca 2013 r. zmieniające rozporządzenie w sprawie warunków technicznych, jakim powinny odpowiadać budynki i ich usytuowanie.

[5] Strzałkowski J.: Ocena przydatności wybranych kompozytów betonowych do wznoszenia ścian zewnętrznych, Praca magisterska, Zachodniopomorski Uniwersytet Technologiczny w Szczecinie, 2012.

\section{THERMAL TRANSMITTANCE IN TWO-LAYER EXTERIOR WALLS WITH VARIOUS CONSTRUCTION MATERIALS}

\section{S u m m a r y}

In this paper we have analysed thermal dynamic characteristics of exterior walls with variant material solutions of used load-bearing layer. The main purpose was to search for the proper solutions of divisions that not only will provide a sufficiently low thermal insulation properties, but also will allow to store energy and use it, depending on the changing conditions of the external environment. Calculations were made for partitions with structural layer made of concrete composites (based on lightweight aggregate made of expanded clay and llytag, additionally varied by air-entraining admixture), cellular concrete, solid laminated wood and other typical brick solutions like sand-lime and cavity bricks. Curves of transmittance module were analysed, depending on a temperature fluctuation period. Decrement factors and surface heat capacities of partitions were also calculated for periods of temperature fluctuations equal 24 and 168h.The results indicate that the inclusion of the specific heat of materials enables more precise assessment of the energy efficiency of the partition. Very good damping properties were obtained for the walls made of concrete composites and solid laminated wood. The results suggest that such solutions provide a much smaller amplitudes of transient heat flux over short periods of temperature fluctuation compared with the materials of low specific heat. Tightened provisions of Directive 2010/31/EU indicate the need for a broader examination of the problem and grounds the need for analysing partitions in non-stationary temperature conditions.

Keywords: exterior walls, thermal transmittance, heat capacity, dynamic thermal characteristics, specific heat

Przestano do redakcji: $19.12 .2014 \mathrm{r}$.

Przyjęto do druku: 22.06.2015 r.

DOI: $10.7862 / \mathrm{rb} .2015 .73$ 